\title{
A Secure Alternative for Electronic Toll Collection using Barcodes
}

\author{
Alese Boniface \\ Kayode \\ The Federal University of \\ Technology \\ School of Computing, \\ Akure, Ondo State, \\ Nigeria
}

\author{
Thompson Aderonke \\ Favour \\ The Federal University of \\ Technology \\ School of Computing, \\ Akure, Ondo State, \\ Nigeria
}

\author{
Ayeni Olaniyi \\ Abiodun \\ The Federal University of \\ Technology \\ School of Computing, \\ Akure, Ondo State, \\ Nigeria
}

\author{
Aliu Folasade Mercy \\ The Federal University of \\ Technology \\ School of Computing, \\ Akure, Ondo State, \\ Nigeria
}

\begin{abstract}
Toll collection is a means of collecting fees from drivers passing a road. The tolls collected are expected to be used in maintaining the roads. To prevent fraud and lack of accountability, a complete electronic operation is needed to collect revenue. Electronic toll collection (ETC) is an automated method of collecting tolls at the toll gates. This work proposes the use of barcodes as a secure alternative for ETC.
\end{abstract}

\section{General Terms}

Wireless Communication and Mobile Computing

\section{Keywords}

Electronic Toll collection, Barcode technology, Toll Booth, Toll Management System

\section{INTRODUCTION}

A toll is a certain amount paid to the toll authorities to gain entry to a road network and be granted access to pass through with a vehicle. Tolls are collected at points known as toll booths or parkways. Manual toll collection has always been demanding and time-consuming. As a result, electronic toll collection (ETC) was introduced to reduce the delays on toll roads through the collection of tolls electronically. It helps in detecting stolen vehicles; reduces the time spent in queues and fuel consumption is minimized. Thus, ETC is more efficient than a manual method of toll collection. There are different technologies used for ETC. However, barcodes are easy to use, less expensive and have international standards. A barcode is a way to cipher information in a graphical design such that it can be read by a machine. The combination of black and white stripes (elements) represents different text characters. A barcode scanner reads these black and white stripes and then transforms them into a line of readable text that can be understood by the computer.

\section{LITERATURE REVIEW}

One of the most important and practical ETC technologies in the globe is centered on DSRC (dedicated short-range communication) which includes barcode and radio frequency identification (RFID) [1]. In [2], a suitable ETC system was proposed to be implemented in Malaysia based on passive RFID tags [2]. The use of RFID technology coupled with an attached cyclometer to provide an effective and wellintensified automated bus ticketing system was recommended in [3]. The automation of the toll collection process by reducing the long queues at toll booths using RFID tags placed on vehicles was also introduced by [4] and [5]. In [6], an Electronic Toll Gate Station using active RFID and ZigBee Technologies was implemented. In [7], an embedded system based on the quick response code, webcam and application program was developed for toll collection in reduced time to prevail over traffic congestion. Furthermore, [8] compared the benefits, functions and characteristics of RFID technology with that of Barcode technology and Quick Response code technology in ETC systems; and further recommended RFID as better technology because it can store more information. However, the security of information was not considered in these research works.

RFID tags can be referred to as dummies because they can only send and receive data without being able to detect whether the signal is being sent from an authorized source or not [9]. As a result of this weakness, requests may be sent from an illegal source, thus leading to the altering of information on a tag. Consequently, when tags are not secured, they are endangered to eavesdropping and denial of service attacks. Furthermore, some low-cost passive tags cannot carry out basic functions such as encryption and hashing, thereby making it easy to hack RFID transponders [10]. According to [11], the presence of mobile phone towers may also stand in the way of RFID signals, thus causing a jam. Other challenges of RFID include a lack of ratified global standards and higher cost [12]. Barcode technology is much more efficient than RFID [13].

An ETC system using barcode reader technology was proposed by [10], [13], and [14]. The systems use labels (barcode) that are placed on the number plate of vehicles, or the front side of vehicles, such that information embedded on the barcode can be read by a barcode scanner. These labels can be easily tampered with or stolen if care is not taken. Besides, the toll charges are also deducted directly from the user's bank account. This also poses a threat.

\section{SYSTEM DESIGN}

\subsection{Barcode Technology}

Barcodes are made up of alternating dark and light lines of different thickness sizes. The dark lines may be thick, medium or tiny. If they are taken in sets of dark and light lines, they represent the digits 0 to 9 . Every time a barcode is checked, a computation is performed to make sure that it has been read correctly. Barcodes are used in library book systems to identify both books and members. They are used in passport 
and ID card systems to represent the passport number or identification number (Leadbetter et al., 2010)[15]. They are used on train tickets to store information about travel dates and routes to be taken. They are also used in automated stock control systems and management systems. A barcode scanner is used to read the particulars which are structured in a barcode and transmit the details back to the computer system, thus making it possible to update its records (Brown et al., 2010)[16]. Barcode scanning is a reliable technology.

\subsection{Toll System Architecture}

The system will make use of four main devices.

- Barcode Tag

- $\quad$ Barcode Reader

- Stand-alone computer

- Central Server

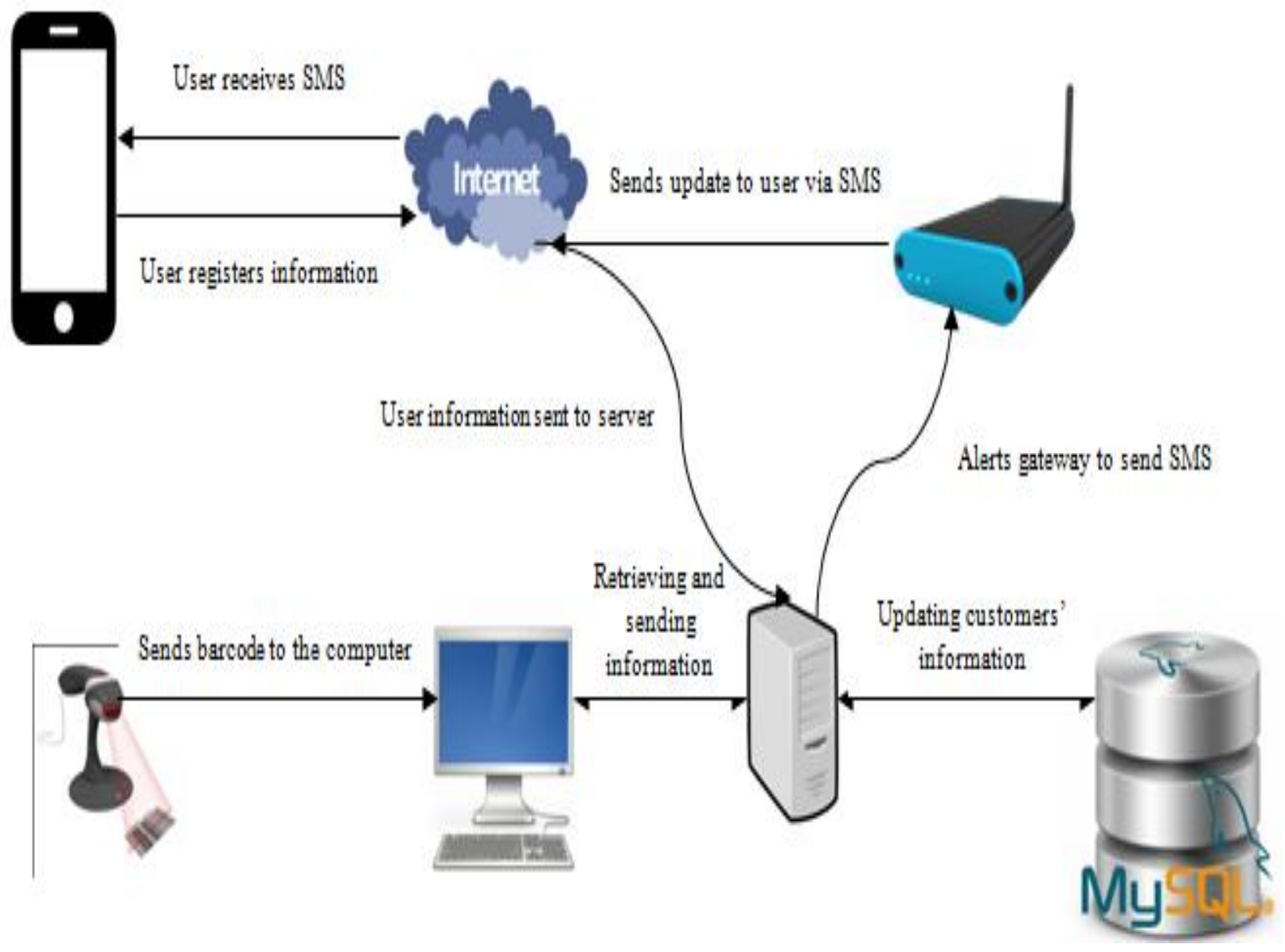

Figure 1: System Architecture

A new user signs up to get an identification code. The identification code will be sent to the client's registered phone number via Short Message Service (SMS). The intending user will use the identification code to $\log$ on to the toll management platform to register his or her details. The client will also pay a certain minimum amount into his wallet. The user's information, such as name, phone number, vehicle name, vehicle type and pre-paid amount, will be stored in the database. The identification code will be used to generate the barcode. The barcode will be printed on a durable plastic card, which should always be available in the vehicle. This will prevent the barcode from being tampered with or damaged, because it is not attached to the vehicle. The flowchart for the toll collection is shown in figure 2 .

\subsection{Toll Collection Process}

At the toll booth, the barcode scanner reads the barcode and sends the retrieved information to the computer (server). If the barcode is identified as genuine, the server checks if the prepaid balance is sufficient for the transaction. If the balance is sufficient for the transaction, a certain amount will be deducted, and the vehicle will be granted access to pass through the toll gate. The account information will be updated on the database and a corresponding SMS will be sent to the customer's registered phone number. If the customer receives an SMS alert that was not authorized by him, he will raise a complaint and the toll gate management will be able to peg any transaction on that account till the issue is resolved. If there are insufficient funds in the pre-paid account, the user will be denied access through the toll gate and face the penalty that will be issued by the law enforcement agency. 


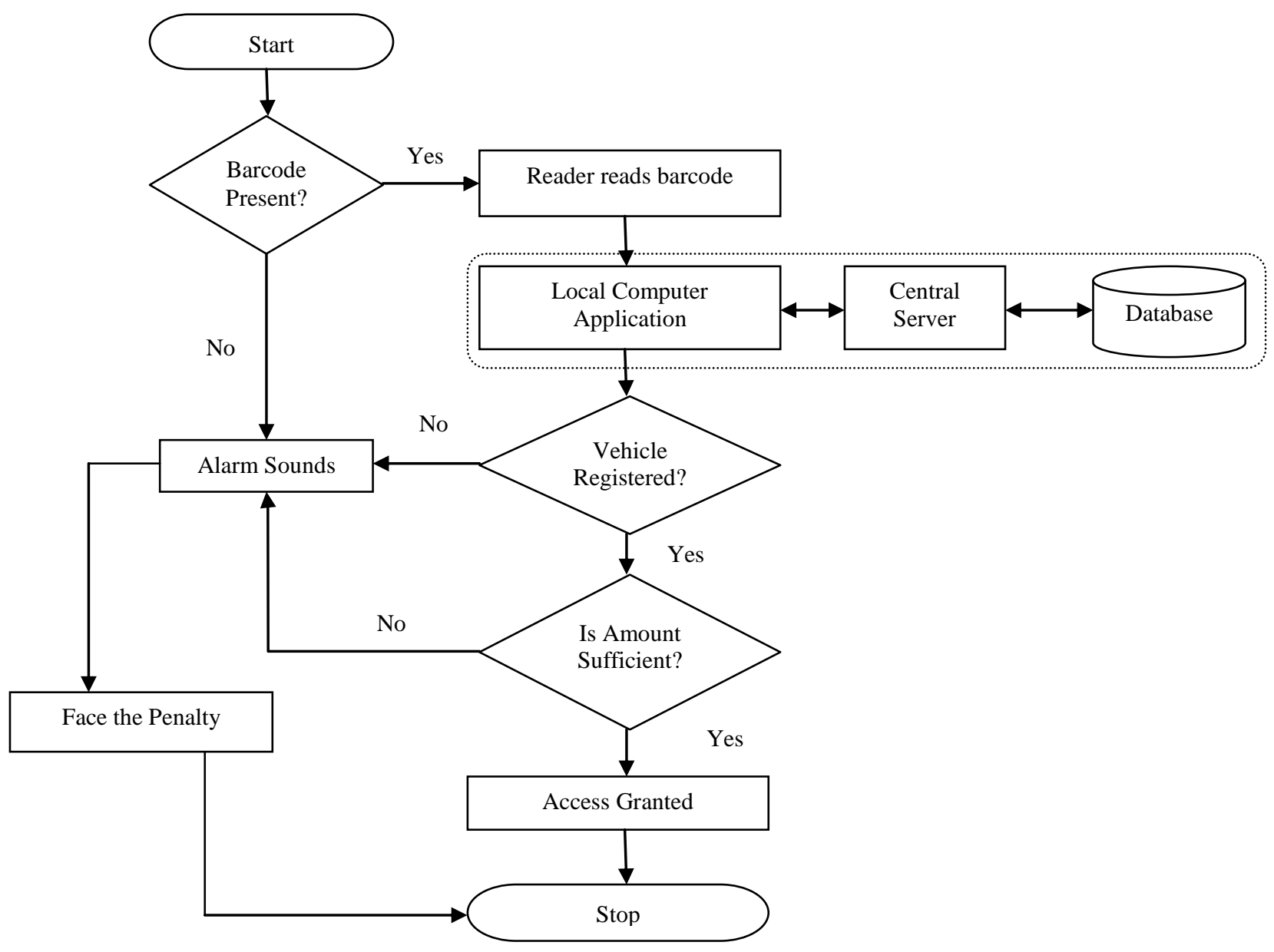

Figure 2: Flowchart for Toll Collection

\subsection{Toll System Implementation}

The implementation of the toll system was done using a toll management system application that has been built with PHP version 7. Data was stored in the MySQL database, which is also open source. The user interface was developed in HTML5, Bootstrap, and JavaScript. The application can run on any web server that supports PHP 7 and has the MySQL database. Browsers include Chrome 36+, Edge 20+, Mozilla Firefox 31+, Internet Explorer 11+ (Windows only), and Safari 6+ (macOS only).
The Operating System requirements are Windows 7, Windows 8 or Windows 10, Mac OSX 10.8, 10.9, 10.10 or 10.11. Hardware requirements are Processor (CPU) with 2 gigahertz $(\mathrm{GHz})$ frequency or above; a minimum of $2 \mathrm{~GB}$ of RAM; monitor resolution of 1024 X 768 or higher; Internet connection broadband (high-speed) with a speed of $4 \mathrm{Mbps}$ or higher; keyboard and a Microsoft mouse or some other compatible pointing device; and a barcode scanner.

\section{Tollgate Management System}

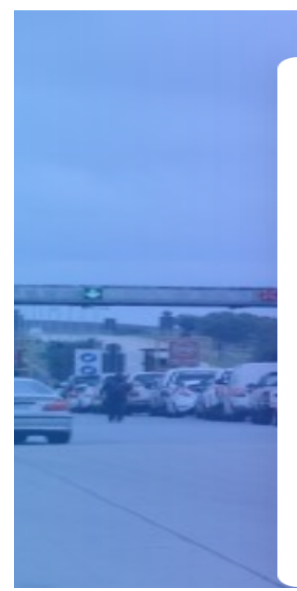

Sign in

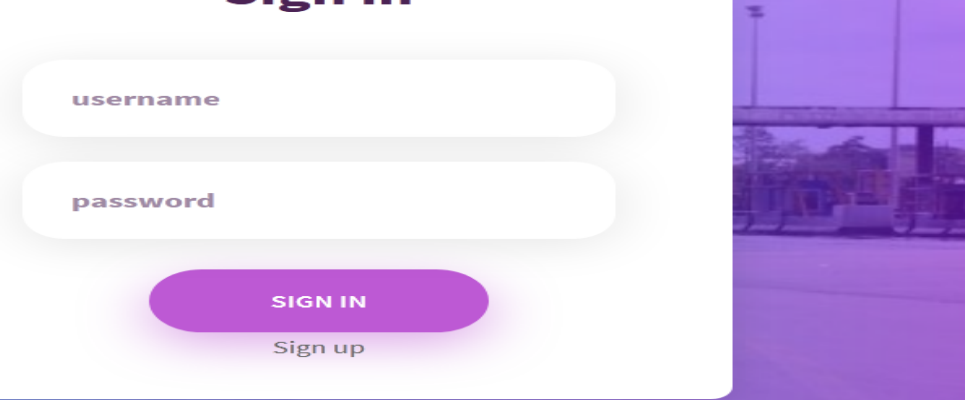

Figure 3: Sign-In Page 
A new user signs up to get an identification code as seen in Figure 3. Existing user signs in using username and password. Once the user signs up, a unique barcode is generated for each registered vehicle. This barcode will be printed on a durable plastic card, not on the vehicle. This will prevent the tags from being tampered with. Each user is required to have the barcode tag in the corresponding vehicle at the time of passing through the toll gate.

\section{TollGate $\quad$ Type for search...}

\section{TollGate}

\section{NAVIGATION}

\section{In Dashboard}
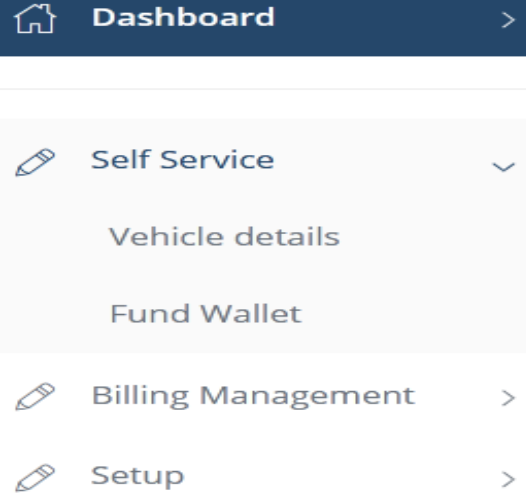

Figure 4: Dashboard (Home Page)

Home Page (Dashboard): This contains three major sections.

- $\quad$ Self Service (Vehicle Details, Fund Wallet): Users enter their vehicle details and fund their wallets.

- Billing Management (Passage Billing): Toll operators scan the barcode and the transaction is done. The client receives an SMS showing details of

\section{TollGate \\ Tollgate Charge \\ in > Charges Billing by Owner}

NAVIGATION

\section{Self Service}

Billing Management

$\&$ Setup
- Setup (Vehicle Category, Vehicle Make, and Vehicle Colour): The toll management sets up the requirements.
Billing \& Verification By Owner

\begin{tabular}{l|l|} 
Identication No * & Toll000015 \\
\hline Full Name & Aliu Folasade \\
\hline Wallet Balance & 6500 \\
\hline Vehicle No & KSF 456 DD \\
\hline Vehicle Type & Car \\
\hline Charge Applied & 100 \\
\hline
\end{tabular}

Figure 5: Billing and Verification Page 
Once the barcode is scanned, the vehicle is confirmed and the transaction takes place.

\section{EXPERIMENTAL ANALYSIS}

The experiment was conducted using 15 barcode tags printed on durable plastic cards. These plastic cards prevent the barcodes from being tampered with, thus making the scanning process a smooth one. Once a tag is scanned, there is an automatic deduction from the user's account, and SMS is received by the user simultaneously. This process ensures transparency. Clients can also access the details of their transaction online through their log-in details. The outcome shows that it takes approximately two seconds (average of 1.6 seconds) to scan a barcode once it is properly positioned. It also requires an average of 2.8 seconds to receive an SMS alert once the barcode is read. Figure 6 shows the time taken to read a barcode and to receive corresponding SMS from the moment the barcode is scanned.

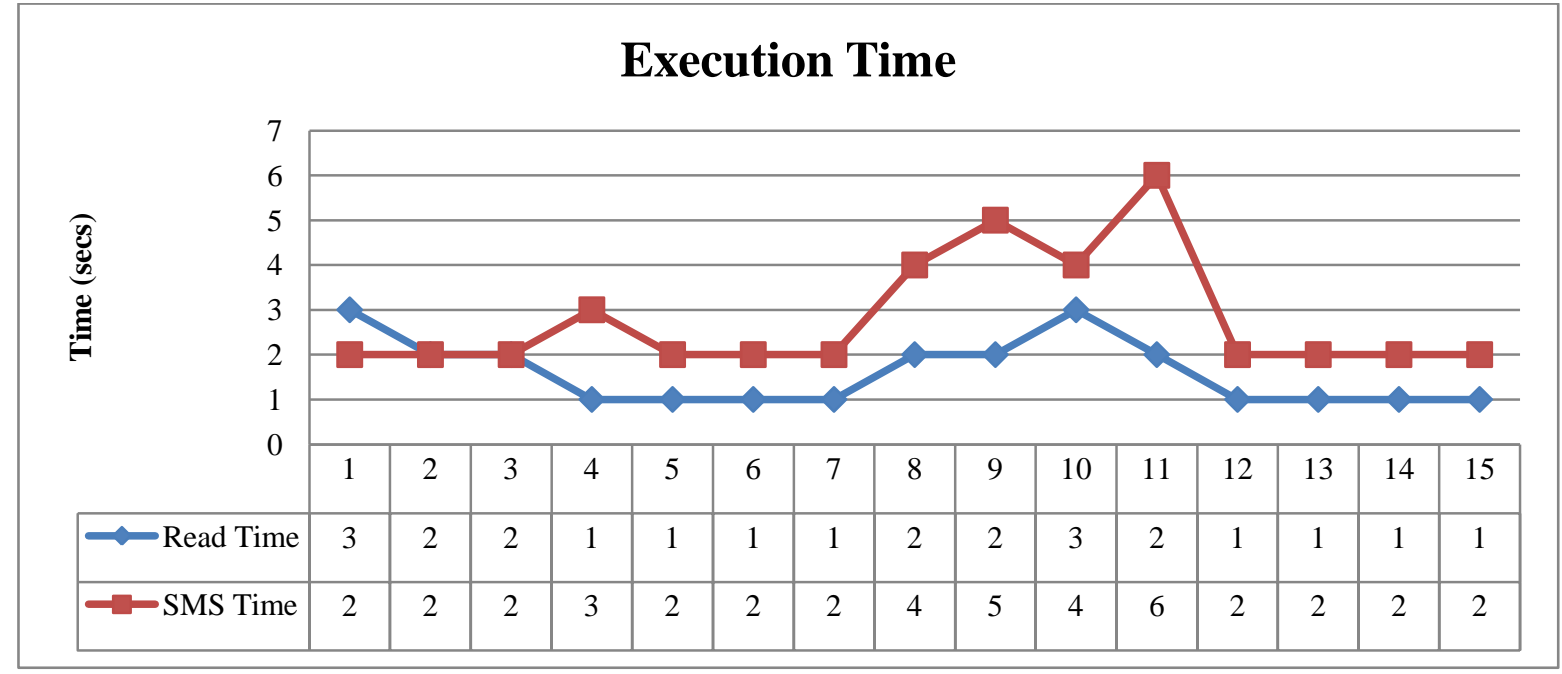

Figure 6: Read Time and SMS Time

Some of the benefits of this system include:

- $\quad$ Affordable cost

- Minimal execution time

- Employment opportunity

- High efficiency

- Security of clients' data

- $\quad$ Ease-of-use

\section{CONCLUSION}

This work proposes an intelligent and secure method of toll collection. A functional program was written to simulate the toll-collection process. The toll collection is done using a barcode scanner to read a barcode that identifies the client and the corresponding vehicle. A certain amount will be deducted from the customer's pre-paid account. The barcode technology is easy-to-use, affordable, secure, quick and efficient. This will prevent fraud and lack of accountability. It will also lower the delays that are caused by manual toll collection.

\section{REFERENCES}

[1] Saurabh, V., Gaurav, V., Rahul, V., \& Varun, K. (2014). Selection of optimal electronic toll collection system for India: A subjective-fuzzy decision-making approach. Applied Soft Computing. https://www.researchgate.net/publication/261884060

[2] Khadijah, K., \& Pdr.Widad, I. (2010). Electronic Toll Collection System Using Passive Rfid Technology. Journal of Theoretical and Applied Information Technology JATIT \& LLS

[3] Varun, K.K.G., Selvarathinam, S., Roopsai V., \& Ram,
K.R.M. (2013) Modified Ticketing System using Radio Frequency Identification (RFID). International Journal of Advanced Computer Research (ISSN (print): 22497277 ISSN (online): 2277-7970) Volume-3 Number-3 Issue-12.

[4] Rakhi, K., Anand, P., Akshay, M., \& Rohan, K. (2014). RFID Based Toll Collection System. (IJCSIT) International Journal of Computer Science and Information Technologies, Vol. 5 (2), 2582-2585 ISSN: 0975-9646

[5] Aniruddha, K., \& Kshitija C. (2014). Automatic Toll Collection System using RFID. International Journal of Electrical and Electronics Research, Vol. 2, Issue 2, pp: (67-72)

[6] Sandhya, V. \& Travin, A. (2012). Automatic Toll Gate Management and Vehicle Access Intelligent Control System Based on ARM7 Microcontroller. International Journal of Engineering Research and Technology. Volume 1, Issue 5. ISSN: 2278-0181

[7] Linda, J., Debyani, M., \& Sayli, M. (2016). Automatic Toll Collection Using QR Code Scanning. International Journal of Advanced Technology in Engineering and Science, Volume No. 4, Special Issue No. 1

[8] Deepashree, M., \& Reshma, M. (2016). A Comparative Study of Different Technologies for Electronic Toll Collection System. International Journal of Innovative Research in Computer and Communication Engineering, Vol. 4, Issue 2.

[9] HKSAR (The Government of the Hong Kong Special Administrative Region). (2008). RFID Security.

[10] Charul, B., Shubham, K., \& Anant, M. (2017). Prepaid 
Toll Collection Using Barcode Reader. International Journal of Innovative Research in Computer and Communication Engineering. Volume 5, Issue 5.

[11] Kalbande, D.R., Singhal, P., Deotale, L., Shah, S., \& Thampi, G.T. (2011). An Advanced Technology Selection Model using Neuro-Fuzzy Algorithm for Electronic Toll Collection System. International Journal of Advanced Computer Science and Applications, Volume 2, Number 4.

[12] Mandeep, K., Manjeet, S., Neeraj, M. \& Parvinder, S. (2011). RFID Technology Principles, Advantages, Limitations \& Its Applications. International Journal of Computer and Electrical Engineering, Vol.3, No.1.

[13] Devika, M., Rohan, K., Sayali, P., \& Amruta, S. (2015). Electronic Toll Collection Using Barcode Reader.
International Journal of Advanced Research in Computer Science and Software Engineering. Volume 5, Issue 2. ISSN: 2277 128X

[14] Sanchit, A., Shachi, G., \& Nidheesh, S. (2014). Electronic Toll Collection System Using Barcode Laser Technology. International Journal of Emerging Trends \& Technology in Computer Science. Volume 3, Issue 2, ISSN 2278-6856.

[15] Leadbetter, C. \& Wainright, S. (2010). IGCSE ICT Coursebook. Cambridge University Press. ISBN 978-0521-17911-9

[16] Brown, G. \& Watson, D. (2010). IGCSE Information and Communication Technology. Hodder Education. ISBN 978-0- 340-983829. 